\title{
Management of cellulitis and the role of the nurse: a 5-year retrospective multicentre study in Fako, Cameroon
}

\author{
Bachi-Ayukokang Ebob-Anya ${ }^{1}$, Nahyeni Bassah ${ }^{1 *}$ (1) and John Ngunde Palle
}

\begin{abstract}
Objective: This was a 5 year retrospective study of patients' hospital records to find out how patients with cellulitis are managed and the care provided by nurses to these patients in some hospitals in Fako, Cameroon.

Results: Of the 236 cases of cellulitis identified from a study of hospital records, 202 were included in the study. Most of the participants (55\%) were female and the mean (SD) age was 43 (1.1) years. Cellulitis accounted for $2.3 \%$ of admissions in this study. The predisposing factors identified were; the presence of trauma (60.5\%), HIV infection (18.6\%), alcohol consumption (8.4\%) and tobacco use (4.8\%). Commonly recorded complications were necrosis (32.2\%), sepsis (23\%), abscess formation (19.5\%), and ulcer development (19.5\%). Medical management was with antibiotic therapy, including mostly penicillin (26.5\%), aminoglycoside (22.1\%), nitroimidazole (20.2\%) and cephalosporin (19.6\%). Debridement (46.7\%), and incision and drainage (44.4\%) were the most implemented surgical interventions. Nursing care, as found in patients' hospital records were predominantly on medication administration (98.0\%), vital signs assessment (90.5\%) and patient assessment (53\%). Cellulitis therefore was found among a substantial number of patients and management was predominantly with combination antibiotics therapy and inadequate nursing care.
\end{abstract}

Keywords: Cellulitis management, Nursing care, Cameroon

\section{Introduction}

Cellulitis, a common medical emergency and cause of infection-related hospital admission worldwide, varies in severity from mild to life threatening $[1,2]$. It is a nonnecrotizing inflammation of the skin and subcutaneous tissue usually caused by Staphylococcus or Streptococcus infection that does not involve the muscle or fascia [3]. It can occur anywhere on the body but its occurrence on the lower limbs is more frequent. There are various risk factors associated with lower extremities cellulitis such as lymphedema, leg edema, venous insufficiency, traumatic wound, leg ulcers, toe-wed intertrigo, and excoriated leg dermatosis [1, 4-7]. Patients with cellulitis may present either at the Out Patient Department (OPD), general

*Correspondence: nahyenibassah@yahoo.com

1 Department of Nursing, Faculty of Health Sciences, University of Buea, P.O Box 63, Buea, South-West Region, Cameroon

Full list of author information is available at the end of the article medical, elderly care, dermatology, orthopedic, vascular or general surgery departments [8].

\section{Main text \\ Study context and study population}

In Cameroon in 2017, Njim et al. [9] found the disruption of the skin barrier and the presence of toe-web intertrigo to be strongly associated with lower limb cellulitis. Moreover, in 2015, cellulitis accounted for 1447 disability adjusted life years (DALYs) in Cameroon and affected mostly men and members in the lower class of society [9, 10]. It is also associated with a prolonged hospital stay, with resultant reduction in income and economic productivity, and consequent worsening of the vicious cycle of poverty [9-11]. The burden of cellulitis has been envisaged to increase in subsequent years in Africa due to the presence of factors such as increasing prevalence of obesity and voluntary depigmentation of the skin [11]. In Cameroon, patients with cellulitis are mostly admitted to the surgical unit, with critical cases in the intensive care 
unit, if available. Those with less severe infections, could be consulted on an outpatient basis, but will require regular outpatient visits for follow up care, as there are no formalized home care services in Cameroon. Moreover, there are currently no guidelines on cellulitis management and treatment is based on the attending healthcare providers' judgment. Nurses in Cameroon play a vital role in patient care in the hospitals as they are the largest group of health professionals and spend more time with patients. They, like other nurses globally, carryout nursing roles like caregiving, communication, patient advocacy, counselling and teaching. Nonetheless, there is a dearth of published literature on the management of cellulitis in Cameroon, and the role played by nurses in this management. This paper therefore presents findings from a study of patients' hospital records that sought to find out how patients with cellulitis are managed and the care provided by nurses to these patients in some hospitals in Fako, Cameroon.

\section{Methods}

The study was carried out in the Fako division in Cameroon, which is one of the six divisions of the SouthWest Region. This region has an estimated population of 1,534,232 (2015) inhabitants and covers a total area of approximately $25,410 \mathrm{~km}^{2}$ [12]. This study was carried out in three healthcare facilities including; one government owned regional hospital, a Cameroon Development Corporation owned Hospital, and a lay private primary health center, specialized in orthopedic care. These health facilities are geographically accessible to the local population.

The study was a retrospective hospital-based cohort study of patients admitted over a 5 year period, from March 2013 to February 2018. Participants included patients admitted to the surgical department of the three selected health services with a primary diagnosis of cellulitis. The sampling strategy was consecutive and exhaustive. The hospital's admission registers were first reviewed and patients with a primary diagnosis of cellulitis, within the study period, were identified. The hospital files of the identified patients were then sorted out from the hospital store and reviewed. The nursing shifts reports for these patients were also identified and studied. Patients with incomplete or missing files were excluded from further analysis.

Data were collected using a researcher-designed checklist, consisting of three sections. "Introduction" section sort information on demographic data and risk factors like: age, sex, religion, ethnic group, marital status, history of alcohol consumption and tobacco use, site of cellulitis infection, phase of infection at consultation (grouped as 'At Onset' which is a period of less than 6 days between apparition of signs and consultation Or 'At later phase' which is above 1 week.) use of self-prescribed medications, systemic symptoms, recurrent infection and presence of a co-morbidity. Section two was on management approaches including medical, and surgical management as well as on nursing care relating to the caregiving, communication, patient advocacy, teaching and counselling roles of the nurse. Nurses' caregiving roles included general patient assessment, vital signs assessment (regulardaily monitoring in the morning, afternoon and evening periods or irregular-omissions of recordings of at least 6 periods), drug administration, hygiene and elimination care, patient feeding pain management, wound care and ambulatory care. Section three was on patient outcome (recorded complications, length of hospital stay and response to treatment).

Data were analyzed using both descriptive (frequency count, percentage and mean) and inferential statistics, with the aid of SPSS version 21. The Chi square test was used to compare phase of infection at consultation with change in regimen for significant difference. Findings were presented on frequency distribution tables and on charts. All statistics were set at $95 \%$ confidence interval.

\section{Results}

All three hospitals had a total of 10,306 admissions during the study period, and 236 of these admissions were cases of cellulitis. Thus cellulitis accounted for $2.3 \%$ of admissions in all facilities combined. However, only 202 patients' files (85.6\%) were included in further analysis, as they were complete. The files of 34 (14.4\%) patients were either incomplete or missing, and thus were excluded. Of the 202 patient studied, 111 (55.0\%) were female, and 91 (45.0\%) males. The mean (SD) age of the participants was 43 (1.1), with range from 1 to 85 years. These participants were from diverse occupational groups but mostly consisted of laborers of the Cameroon Development Corporation $(24.3 \%)$, farmers $(16.3 \%)$, traders $(8.4 \%)$, students (6.1\%) and housewife (6.1\%) (Table 1). Trauma (60.5\%), HIV (18.6\%), alcohol consumption (8.4\%) and tobacco use $(4.8 \%)$ were most predominant predisposing factors (Table 2).

The highest number of admissions occurred in the month of December with a total of 26 cases $(12.9 \%)$, followed by August [23 (11.4\%)], July [21 (10.4\%)], and November [20 (9.9\%)]. Admissions were least common in the month of May, with only 8 admissions. A steady increase was seen in number of cases from year 2 to 5 (Additional file 1). Seventy-six (37.6\%) patients consulted at onset of their infection, while 70 (34.7\%) consulted at the later phase. Fifty-six (27.7\%) case files had no indication on when signs and symptoms started. Thirtythree $(16.3 \%)$ of the patients had consulted previously 
Table 1 Demographic data of cellulitis patients

\begin{tabular}{|c|c|c|c|}
\hline \multirow{2}{*}{$\begin{array}{l}\text { Demographic } \\
\text { information }\end{array}$} & \multirow{2}{*}{$\begin{array}{l}\text { Test statistics } \\
\text { Categories }\end{array}$} & \multicolumn{2}{|c|}{ Statistical values } \\
\hline & & Frequency & Percentage (\%) \\
\hline \multirow[t]{6}{*}{ Age in categories } & $0-14$ & 6 & 3.0 \\
\hline & $15-24$ & 10 & 5.0 \\
\hline & $25-44$ & 102 & 50.5 \\
\hline & $45-64$ & 63 & 31.2 \\
\hline & $65+$ & 21 & 10.4 \\
\hline & Total & 202 & 100.0 \\
\hline \multirow[t]{3}{*}{ Sex } & Female & 111 & 55.0 \\
\hline & Male & 91 & 45.0 \\
\hline & Total & 202 & 100.0 \\
\hline \multirow[t]{12}{*}{ Occupation } & CDC laborer & 49 & 24.3 \\
\hline & Local farmer & 33 & 16.3 \\
\hline & Business & 17 & 8.4 \\
\hline & Student & 13 & 6.1 \\
\hline & House wife & 13 & 6.1 \\
\hline & Jobless & 12 & 5.9 \\
\hline & Retired & 11 & 5.4 \\
\hline & Tapper & 7 & 3.5 \\
\hline & Driver & 6 & 3 \\
\hline & Not recorded & 16 & 7.9 \\
\hline & Others & 25 & 12.5 \\
\hline & Total & 202 & 100 \\
\hline
\end{tabular}

Table 2 Other Risk factors associated with the development of cellulitis

\begin{tabular}{lcc}
\hline Predisposing factors & Responses N & Percentage (\%) \\
\hline Trauma & 101 & 60.5 \\
HIV & 31 & 18.6 \\
Alcohol & 14 & 8.4 \\
Tobacco & 8 & 4.8 \\
Carbuncle & 4 & 2.4 \\
Obesity & 3 & 1.8 \\
Existing ulcer & 2 & 1.2 \\
Athlete foot & 1 & 0.6 \\
Dental origin & 1 & 0.6 \\
Steroid induced cushing syndrome & 1 & 0.6 \\
Malnutrition & 1 & 0.6 \\
Total & 167 & 100.1
\end{tabular}

before their contact with the study hospitals. The lower limb was the most common lesion site, with 188 (93.0\%) of cases. Eight (4.0\%) of the patients had cellulitis on their upper limb and $6(3.0 \%)$ on the face. Up to $52(25.7 \%)$ cases presented with one or more systemic symptoms such as fever, headache and lymphadenitis. A few of the patients (12.4\%) received self-prescribed medications such as antibiotics, analgesics and traditional remedies before consultation. Moreover, 17 (8.4\%) cases experienced a reoccurrence of infection. Sixty-seven (33.2\%) cases had their infection associated with complications such as necrosis $(32.2 \%)$, sepsis $(23 \%)$, abscess formation (19.5\%), ulcer (19.5\%), deep vein thrombosis (3.4\%), pussy pustules (1.1\%) and lymphangitis (1.1\%). Complete recovery was registered for 178 (88.1\%) patients while fourteen (6.9\%) were discharged against medical advice, $5(2.5 \%)$ were referred, 3 (1.5\%) died and 2 (1.0\%) absconded from the hospital. The mean (SD) length of hospital stay was 11.2 (0.7) days, with a range from 1 to 74 days.

All patients were placed on antibiotic therapy, with $30(15 \%)$ on mono-antibiotic therapy and $172(85 \%)$ on combination therapy. Out of those placed on combination therapy, 114 patients $(56.4 \%)$ were placed on 2 antibiotics, $52(25.7 \%)$ placed on 3 antibiotics, 5 (2.5\%) were placed on 4 antibiotics and $1(0.5 \%)$ placed on 5 antibiotics. Penicillin (26.5\%), aminoglycoside (22.1\%), nitro imidazole (20.2\%) and cephalosporin (19.6\%) were the most common antibiotics used (Additional file 2). Ninety-one patients $(45 \%)$ had their antibiotic regimen changed along the course of treatment, $62.6 \%$ of who were those who consulted at the onset of infection while $37.4 \%$ where those who consulted at a later phase. The mean (SD) duration of the antibiotic regimen was $9.47(0.4)$ days.

Forty-five (19.8\%) patients underwent surgical interventions, these included wound debridement 21 (46.7\%), abscess incision and drainage $20(44.4 \%)$, skin grafting 3 (6.7\%) and 1 amputation (2.2\%) (Additional file 3). One hundred and seven (53.0\%) patients had their health history assessed and recorded by a nurse. The vital signs for $99(49.0 \%)$ patients were regularly checked and that for $94(46.5 \%)$ patients were irregularly assessed and recorded. Twenty-three patients $(11.4 \%)$ had cold compress applications and 198 (98.0\%) had their medications administered and recorded in their files. Generally, there was almost no record of patient education in the files. However, in $2.5 \%$ of files patients were reported to have received education about their nutrition (Table 3 ).

\section{Discussion}

Cellulitis was found among a substantial number of patients in the study setting. Nonetheless, the incidence is lower when compared to the study of Concheiro et al. in Western Australia who recorded 8.6\% [13]. This difference could be attributed to the fact that their study was carried out in a more specialized dermatology department which narrows down the number of admissions whereas our study was done in the surgical unit. In line with other studies $[8,9,13]$ our study revealed a higher female to male ratio, which was not the case 
Table 3 Care provided and recorded by nurses

\begin{tabular}{|c|c|c|c|c|}
\hline Nursing role & Nursing interventions & Recorded & Number of cases & Percentage (\%) \\
\hline \multirow[t]{11}{*}{ Care giver } & \multirow[t]{3}{*}{ History taking and physical assessment } & Yes & 107 & 53 \\
\hline & & No & 95 & 47 \\
\hline & & Total & 202 & 100 \\
\hline & \multirow[t]{4}{*}{ Vital signs assessment } & Regularly & 99 & 49 \\
\hline & & Irregularly & 94 & 46.5 \\
\hline & & Never & 9 & 4.5 \\
\hline & & Total & 202 & 100 \\
\hline & Care provision & & Number of cases & Percentage (\%) \\
\hline & Application of a cold compress & & 23 & 11.4 \\
\hline & Nursing care plan & & 2 & 1 \\
\hline & Medication administration & & 198 & 98 \\
\hline \multirow[t]{3}{*}{ Educator } & Patient education and area & & Number of cases & Percentage (\%) \\
\hline & Nutritional education & & 5 & 2.5 \\
\hline & Prevention of recurrent infection & & 1 & 0.5 \\
\hline
\end{tabular}

with previous studies $[1,14,15]$. In our setting, women are more likely to be involved in farming where they are exposed to injuries that predisposes them to cellulitis. Cellulitis was also common among young adults and this is consistent with a previous report [15]. Young adults make a majority of the work force population hence increasing the possibility of trauma and consequent infection. Moreover, most of those affected in this study were local farmers and laborers of the Cameroon Development Corporation, who are predominantly young adults, and who do not have adequate protective tools like gloves and booths. Trauma, was therefore a common risk factor of cellulitis in this study as in previous studies $[8,9,11,13,16]$.

The patients in this study were most likely to visit these healthcare facilities after having consulted elsewhere or taken self prescribed medications, like NSAIDs, antibiotics or traditional remedies $[8,11,13]$. It is worth noting that these hospitals serve as reference hospitals for surgical cases in this setting. Interestingly, the percentage of patients who had complications was small compared to the perception of development of life threatening complications as stated in literature [14].

A majority of the patients in our study were placed on combination therapy, similar to the previous reports by Aly et al. [17]. Almost half of the patients had their regimen changed, and this was fourfolds higher than the value reported by Dong et al. [18]. Surprisingly, a majority of the patients with regimen change were those who came to the hospital at the onset of the infection. The reason for this is not quite evident. Nevertheless, we noted that the mean duration of antibiotics use in this study is longer than the recommended 5 days by the Infectious
Disease Society of America 2014 guidelines for the diagnosis and management of skin and soft tissue infection [19].

Generally, nurses were seen to play a limited role in the management of cellulitis in these health facilities, as was found in patients' hospital records and nurses' shift reports. The role of the nurse in health assessment includes obtaining a history and performing a physical assessment [20]. Nurses need to be able to recognize the manifestation of cellulitis so as to rule out other conditions and commence therapy immediately [21]. In line with this, a good number of cases were assessed by nurses upon admission and throughout their hospital stay. On the other hand, only few patients received fundamental nursing care, and this was limited to medication administration and application of a cold compress. This practice is contrary to the use of a warm compress as recent literature states [20]. As concerns education, the number of patients who were educated is negligible. The failure of nurses to get a firm grip on this aspect of care renders patients unaccustomed to their practices [22]. Educating patients can assist recovery and adherence to treatment. Generally, most expected nursing roles were either left undone or unrecorded.

Documentation is a daily reality of nurses' work as it gives evidence to the care rendered by nurses and hence negligence of this role is one of the causes of the existence of alternative knowledge in nursing practice [23]. The implementation and documentation of the nursing process in all patient-nurse care encounters is an ideal that has challenged the nursing profession and discipline [24]. In conjunction with this, whether the nurses in these health facilities did render high standards of care or 
not, we could not fully appreciate their work due to inadequate documentation.

In conclusion there was an integrated management of cellulitis, however, this was marked by use of antibiotics combination therapy, and inadequate nursing care provision.

\section{Limitations}

Our study was carried out in the surgical units and did not include the out-patient and intensive care units hence the exact incidence for these hospitals is not reflected in our study. Moreover, this study was conducted in only three hospitals in Fako, limiting the possibility of generalizing the findings to the entire population of Fako. In addition, due to poor documentation, our study could not fully identify predisposing factors, and the role of the nurse. Thus these results should be taken with caution.

\section{Additional files}

Additional file 1. Figure showing distribution of cellulitis cases per year per month.

Additional file 2. Figure showing antibiotics administered to patients. Additional file 3. Table showing the types of surgical managent recieved by patients.

\section{Abbreviations}

HIV: human immunodeficiency virus; OPD: out patient department; DALY: disability adjusted life years; SPSS: statistical package for social sciences; SD: standard deviation; NSAID: non-steroidal anti-inflammatory drug.

\section{Acknowledgements}

The authors will like to thank the healthcare facilities for giving us access to their hospital records.

\begin{abstract}
Authors' contributions
$B A, N B$, and JNP participated in the methodological assessment and design of the study. BA collected and analysed the data under the academic supervision of NB and JNP. BA wrote the initial draft of this paper and NB and JNP gave comments on all the subsequent and final version of the paper. All authors read and approved the final manuscript.
\end{abstract}

\section{Funding}

The study was funded from the authors' personal funds.

\section{Availability of data and materials}

The datasets used during the current study are available from the corresponding author on reasonable request.

\section{Ethical approval and consent to participate}

Ethical approval for this study was obtained from the Institutional Review Board of the Faculty of Health Sciences, University of Buea (2018/210/UB/SG/ IRB/FHS). In addition, administrative authorization to access the various health facilities for data collection was obtained from the Regional Delegation of Public Health and the authorities of the respective healthcare institutions. The researchers also ensured honesty, objectivity and confidentiality throughout the study.

\section{Consent to publish}

Not applicable.

\section{Competing interests}

The authors declare that they have no competing interests.

\section{Author details}

${ }^{1}$ Department of Nursing, Faculty of Health Sciences, University of Buea, P.O Box 63, Buea, South-West Region, Cameroon. ${ }^{2}$ Saint Luke's Medical Center Buea, Buea, Cameroon.

Received: 29 April 2019 Accepted: 17 July 2019

Published online: 23 July 2019

\section{References}

1. Björnsdóttir S, Gottfredsson M, Thórisdóttir A, Gunnarsson GB, Ríkardsdóttir H, Kristjánsson M, et al. Risk factors for acute cellulitis of the lower limb: a prospective case-control study. Clin Infect Dis. 2005:41:1416-22

2. Albuainain KM, Aljuwayd AA, Almarzouq AA, Abu AISaud ZAA, Mazaid Alkhattaf NA, Alabdrabalraso EA, et al. Causes and management of cellulitis. Egypt J Hosp Med. 2018;70:2148-51.

3. Osborn KS, Wraa CE, Watson AB, Holleran R. Medical surgical nursing. 2nd ed. London: Pearson Education; 2014.

4. Dupuy A, Benchikhi H, Roujeau JC, Bernard P, Vaillant L, Chosidow O, et al. Risk factors for erysipelas of the leg (cellulitis): case-control study. BMJ. 1999;318:1591-4.

5. Roujeau JC, Sigurgeirsson B, Korting HC, Kerl H, Paul C. Chronic dermatomycoses of the foot as risk factors for acute bacterial cellulitis of the leg: a case-control study. Dermatol. 2004;209:301-7.

6. Semel JD, Goldin H. Association of athlete's foot with cellulitis of the lower extremities: diagnostic value of bacterial cultures of ipsilateral interdigital space samples. Clin Infect Dis. 1996;23:1162-4.

7. Pitché P, Diatta B, Faye O, Diané BF, Sangaré A, Niamba P, et al. Risk factors associated with leg erysipelas (cellulitis) in sub-Saharan Africa: a multicentre case-control study. BMC Dermatol. 2015;142:633-8.

8. Cox NH, Clover GB, Peterson WD. Management and morbidity of cellulitis of the leg. J R Soc Med. 1998;91:634-7.

9. Njim T, Ndemnge LA, Agbor VM, Toukam LD, Kashaf SS, Ohuma EA. Risk factors of lower limb cellulitis in a level-two health care facility in Cameroon: a control-case study. BMC Infect Dis. 2017;17:418.

10. GBD 2015 DALYs and HALE Collaborators. Global, regional, and national disability-adjusted life-years (DALYs) for 315 diseases and injuries and healthy life expectancy (HALE), 1990-2015: a systemic analysis for the Global Burden of Disease Study 2015. Lancet. 2016;388:1603-58.

11. Tianyi F-L, Mbanga CM, Danwang C, Agbor VN. Risk factors and complications of lower limb cellulitis in Africa: a systematic review. Br Med J Open. 2018;8:e021175.

12. Cameroon data portal. South-West. http://cameroon.opendataforafri ca.org/apps/atlas/South-West. Accessed 24 Feb 2019.

13. Concheiro J, Loureiro M, González-Villas D, Gracia-Gavin J, Sánchez-Aguilar D, Toribio J. Erysipelas and cellulitis: a retrospective study of 122 cases. Actas Dermo-Sifiliográficas. 2009;100:888-94.

14. Ellis Simonsen SM, van Orman ER, Hatch BE, Jones SS, Green LH, Hegmann KT, et al. Cellulitis incidence in a defined population. Epidemiol Infect. 2006:134:293-9.

15. Anjrini AA, Kruger E, Tennant M. A 10-year retrospective analysis of hospitalization for oral cellulitis in Australia: the poor suffer at 30 times the rate of the wealthy. J Istanbul Univ Faculty Dentist. 2014;5:8-13.

16. Karppelin M, Siljander T, Vuopio-Varkila J, Kere J, Huhtala H, Vuento R, et al Factors predisposing to acute and recurrent bacterial non-necrotizing cellulitis in hospitalized patients: a prospective case-control study. Clin Microbiol Infect. 2010;16:729-34.

17. Aly AA, Neil MR, Seipol KS, MacLellan DG. Case survey of management of cellulitis in a tertiary teaching hospital. Med J Aust. 1996;165:553-6.

18. Dong SL, Kelly KD, Oland RC, Holroyd BR, Rowe BH. ED management of cellulitis: a review of five urban centers. Am J Emerg Med. 2001;19:535-40.

19. Dennis LS, Alan LB, Chambers HF, Patchen D, Ellie JCG, Gorbach SL, Hirschmann JV, Sheldon LK, Montoya JG, Wade JC. Practice guidelines for the diagnosis and management of skin and soft tissue infection: 
2014 update by the Infectious Disease Society of America. Clin Infect Dis. 2014;59(2):e10-52.

20. Smetzer SCO, Bare BG. Medical-Surgical Nursing. 10th ed. Philadelphia: Lippincott Williams \& Wilkins; 2004.

21. Beasley A. Management of patients with cellulitis of the lower limb. Nurs Stand. 2011;26:50-5.

22. Heartfield M. Nursing documentation and nursing practice: a discourse analysis. J Adv Nurs. 1996;24:98-103.

23. Tilley JD, Gregor FM, Thiessen V. The nurses' role in patient education: incongruent perceptions among nurses and patients. J Adv Nurs. 1987;12:291-301.
24. Cruz DALM, Guedes ES, Santos MA, Sousa RMC, Turrini RNT, Maia MM, et al. Nursing process documentation: rationale and methods of analytical study. Revista Brasileira de Enfermagem. 2016;69:183-9.

\section{Publisher's Note}

Springer Nature remains neutral with regard to jurisdictional claims in published maps and institutional affiliations.
Ready to submit your research? Choose BMC and benefit from:

- fast, convenient online submission

- thorough peer review by experienced researchers in your field

- rapid publication on acceptance

- support for research data, including large and complex data types

- gold Open Access which fosters wider collaboration and increased citations

- maximum visibility for your research: over $100 \mathrm{M}$ website views per year

At BMC, research is always in progress.

Learn more biomedcentral.com/submissions 